\title{
BMJ Open Lived experiences of patients with placenta accreta spectrum in Utah: a qualitative study of semi- structured interviews
}

\author{
Brett D Einerson (D , ${ }^{1}$ Melissa H Watt, ${ }^{2}$ Brittney Sartori, ${ }^{3}$ Robert Silver, ${ }^{1}$ \\ Erin Rothwell ${ }^{1}$
}

To cite: Einerson BD, Watt MH, Sartori B, et al. Lived experiences of patients with placenta accreta spectrum in Utah: a qualitative study of semi-structured interviews. BMJ Open 2021;11:e052766. doi:10.1136/ bmjopen-2021-052766

- Prepublication history for this paper is available online. To view these files, please visit the journal online (http://dx.doi. org/10.1136/bmjopen-2021052766).

Received 29 April 2021 Accepted 30 September 2021

Check for updates

(C) Author(s) (or their employer(s)) 2021. Re-use permitted under CC BY-NC. No commercial re-use. See rights and permissions. Published by BMJ.

${ }^{1}$ Department of Obstetrics and Gynecology, University of Utah Health, Salt Lake City, Utah, USA ${ }^{2}$ Department of Population Health Sciences, University of Utah Health, Salt Lake City, Utah, USA

${ }^{3}$ College of Nursing, University of Utah Health, Salt Lake City, Utah, USA

Correspondence to Dr Brett D Einerson; brett.einerson@hsc.utah.edu

\section{ABSTRACT}

Objective To describe the lived experience of patients undergoing diagnosis and treatment of placenta accreta spectrum (PAS).

Design Qualitative study of semi-structured interviews. A content analysis was used to analyse interview data using a consistent set of codes to designate data segments that contain similar material. Codes were analysed and grouped based on thematic similarities. Thematic results were systematically reviewed, verified and audited to address trustworthiness and rigour of the data and analysis.

Setting A single PAS programme in Utah, USA, from 2017 to 2020 .

Participants Patients with PAS during the study period were eligible. Those experiencing fetal demise or termination were excluded. Of 25 patients contacted at random, 17 agreed to participate in interviews. Those included were predominantly non-Hispanic white, highly parous, with average age of 34.7 years.

Results The lived experiences of patients with PAS emerged across the time continuum from diagnosis, pregnancy, birth, to postpartum care and recovery. Themes common across the care continuum were: the emotional burden of diagnosis and management; fear and uncertainty related to health outcomes; and lack of autonomy and medical helplessness related to medical decision-making. Many patients experienced birth-related trauma, mourned the loss of future fertility and were dissatisfied with the lack of options for treatment for this serious pregnancy complication.

Conclusions Patients undergoing diagnosis and treatment for PAS often experienced care that conflicted with their goals for pregnancy and birth. Clinical care for PAS would benefit from interventions aiming to engage patients and providers in shared decision-making and systems designed to address the social, psychological and emotional needs of patients with PAS.

\section{INTRODUCTION}

Placenta accreta spectrum (PAS) is a potentially life-threatening complication affecting 1-3 per-thousand pregnancies, with up to 10000 cases annually in the USA. ${ }^{2}$ PAS is characterised by abnormal attachment and
Strengths and limitations of this study

- One of few studies describing the lived experience of patients with placenta accreta spectrum, and the largest study of interviews in this patient group.

- Use of rigorous and validated qualitative methods in interviewing, analysis and interpretation to avoid investigator bias.

- Generalisability may be limited by a participant population that was relatively racially/ethnically homogeneous, high in parity and from a single centre.

adherence of the placenta to the uterus. ${ }^{3}$ At the time of delivery, the placenta does not easily detach as it would in normal pregnancies, and if forcefully removed, often results in massive bleeding. In severe cases of PAS, $1 \%-7 \%$ of patients die. ${ }^{4-8}$

PAS is typically diagnosed in the second or third trimester of pregnancy. Due to the risk of catastrophic and unpredictable bleeding during pregnancy, patients should be closely monitored and be within a short driving distance of a tertiary medical centre that can provide emergency obstetric care. The standard treatment for PAS in the USA includes early delivery (at 34-36 weeks' gestation) by caesarean, avoiding removal of the placenta and immediate hysterectomy with the uterus and placenta removed concurrently. Due to the complicated procedure, many patients undergo general anaesthesia for the entire surgery. Heavy, life-threatening bleeding is common during surgery, with up to $85 \%$ requiring blood transfusion and many requiring intensive care and prolonged hospitalisation. $^{4-8}$ The immediate recovery can be more painful and difficult than a typical caesarean delivery, and bonding and breast feeding may be inhibited due to newborn prematurity and need for intensive monitoring after delivery. Although the immediate 
medical complications of PAS are well described, we are only now beginning to understand the longer-lasting physical health issues, emotional and psychological sequelae and quality of life issues common to survivors of PAS. ${ }^{9} 10$

Descriptions of the lived patient experience of PAS are largely absent from the medical literature. The journey through diagnosis, management, treatment and recovery may be confusing, terrifying and expensive. ${ }^{11}{ }^{12}$ Because of the focus on the serious and immediate medical issues, providers may miss or underestimate the short-term and long-term psychological, social and emotional toll of PAS on patients and their families. Thus, our goal was to describe the lived experience of patients diagnosed with PAS. A better understanding of the perspective of patients with PAS is needed so that adequate resources and attention can be allocated to anticipating and addressing the needs of patients diagnosed with this complex and morbid pregnancy complication.

\section{METHODS}

This was a qualitative study involving interviews with patients in the Utah Placenta Accreta Program. All participants were sent a consent cover letter prior to the interview. Before conducting the interview, the interviewer asked participants if they had any questions and reminded them that, by agreeing to be recorded and interviewed, they were providing consent to participate. Patients with PAS who delivered in a 3-year period (20172020) at the study hospital were eligible for interview. We excluded patients who experienced fetal demise or pregnancy termination as part of their treatment, since these events likely alter patient experience. To achieve the goal of at least 15 participants, we contacted 25 eligible patients randomly from the study period, and 17 agreed to be interviewed. $\mathrm{X}^{2}$ and Wilcoxon rank-sum tests were used to evaluate differences between participants and non-participants. A p value of 0.05 was used to determine statistical significance. This manuscript followed the Standards for Reporting Qualitative Research. ${ }^{13}$

Interviews were conducted in November and December, 2020. A member of the research team experienced in qualitative research (ER) conducted the interviews over the telephone. The semi-structured interview guide was developed based on review of available literature and input from the research team to capture experiences, perspectives and decision needs. Open-ended questions invited participants to speak about their experiences with PAS, including 'Please tell me how you first found out you had PAS.'; 'Can you describe what type of support you received for PAS?'; 'What would have helped you the most during this process?'. The interviewer used nondirective probes to seek additional detail and description from the participants. ${ }^{14}$ Interviews were audio recorded with participant consent, and transcribed by a professional transcription service. Interviews lasted on average 24.5 min. Dedoose V.7.0.23 software was used to analyse, retrieve and review all coded data. ${ }^{15}$
A qualitative content analysis was used for analysis. A distinguishing feature of content analytical approaches is the use of a consistent set of codes to designate data segments that contain similar material. ${ }^{16}$ Consistent with previous research, the codes were generated from the interview guide and inductively from data, based on careful reading of the text, consideration of context and alignment with research objectives. ${ }^{17}$ The coding template was then systematically applied to the transcripts (BS), with the ability to add codes that might have been missed with the initial development of the codebook. ${ }^{16}$ Throughout the data analysis process, team meetings were conducted to review the coding and assess saturation. No new codes were identified after the first eight transcripts, but additional interviews were conducted to ensure the meaning and depth of experiences were captured. ${ }^{18}$ After coding was completed, the codes were grouped together based on thematic similarities. An additional researcher (ER) independently read the coded data for accuracy and to identify cross-cutting themes across the interviews. ${ }^{19} 20$

On completion of the coding, all data were queried by the codes and reviewed by the research team. The research team included two population health scientists, a nurse midwife and an obstetrician with expertise in PAS. This allowed reviewing, verifying and auditing the coding schema and associated data, and addressed trustworthiness and rigour of data during the analysis through methods of credibility and auditability. We followed the qualitative research approach of reflexivity to minimise the influence of our own beliefs on data analysis. ${ }^{21}$ Our personal beliefs, assumptions and roles were continually discussed by the team during the analysis to prevent premature interpretations of data and to recognise assumptions. ${ }^{22}$

\section{Patient and public involvement}

Patients were interview participants in this study. Patients and patient advocates reviewed and confirmed key findings in this study to assess for validity and reproducibility. Patient advocates are involved in the planned dissemination of these findings via advocacy groups, forums, blogs and social media.

\section{RESULTS}

The 17 participants were predominately non-Hispanic white, with an average age of 34.7 years, an average number of four children and an average time of 1.9 years since delivery and treatment for PAS (see table 1). All patients had antenatal diagnosis and 16 of 17 underwent planned caesarean hysterectomy (1 conservative uterine-sparing management). Select clinical outcomes include: median surgical blood loss $2500 \mathrm{~mL}$ (IQR 1500-3393), ICU admission in 2 and median hospital length of stay 5 days (IQR 4-5). The final histopathological diagnosis was accreta in 6 , increta in 4 and percreta in 7. There were no meaningful differences in race/ ethnicity, parity, antenatal diagnosis, disease severity 
Table 1 Sample characteristics $(n=17)$

\begin{tabular}{|c|c|c|}
\hline Age at enrolment (years) & & $34.7(5.0)$ \\
\hline $\begin{array}{l}\text { Time between delivery } \\
\text { and interview (months } \\
\text { (range)) }\end{array}$ & & $23(7-38)$ \\
\hline Race & White or Caucasian & 15 \\
\hline & Pacific Islander & 1 \\
\hline & $\begin{array}{l}\text { American Indian or Alaska } \\
\text { Native }\end{array}$ & 1 \\
\hline
\end{tabular}

\begin{tabular}{|c|c|c|}
\hline Ethnicity & Non-Hispanic & 17 \\
\hline \multirow[t]{6}{*}{ Income } & Less than US\$25000 & 1 \\
\hline & US\$25 001-US\$34999 & 2 \\
\hline & US\$35 000-US\$49999 & \\
\hline & US\$50 000-US\$74999 & 3 \\
\hline & US\$75000-US\$99999 & 5 \\
\hline & Over US\$100000 & 6 \\
\hline \multirow[t]{4}{*}{ Education } & $\begin{array}{l}\text { Less than high school } \\
\text { diploma }\end{array}$ & 2 \\
\hline & Some college & 5 \\
\hline & College degree & 9 \\
\hline & Graduate degree & 1 \\
\hline \multirow[t]{3}{*}{ Relationship } & Married & 15 \\
\hline & Significantly involved & 1 \\
\hline & Single & 1 \\
\hline \multirow[t]{4}{*}{ Religion } & Christian & 3 \\
\hline & Latter-day Saints/Christian & 9 \\
\hline & Catholic & 1 \\
\hline & Not religious & 4 \\
\hline \multirow{7}{*}{$\begin{array}{l}\text { How many children } \\
\text { including this one do } \\
\text { you have? }\end{array}$} & One & 1 \\
\hline & Two & 1 \\
\hline & Three & 2 \\
\hline & Four & 8 \\
\hline & Five & 2 \\
\hline & Six & 2 \\
\hline & Eight & 1 \\
\hline $\begin{array}{l}\text { How many weeks } \\
\text { pregnant at diagnosis? }\end{array}$ & & $23.4(6.1)$ \\
\hline $\begin{array}{l}\text { How many weeks when } \\
\text { delivered? }\end{array}$ & & $33.3(2.7)$ \\
\hline
\end{tabular}

Presented as mean (SD), except when noted.

(accreta, increta, percreta) or clinical outcomes and management in participants who did and did not agree to participate.

Themes related to participants' lived experiences with PAS emerged across the time continuum of (1) diagnosis, (2) pregnancy, (3) birth and (4) postpartum care and recovery. Themes were identified that were both unique to specific time periods, as well as those that cut across the continuum of care (figure 1).

\section{Diagnosis}

Three themes were identified specific to the diagnosis of PAS: emotional distress, difficult provider communication and medical helplessness. Participants described how the emotional distress of the diagnosis typically started with a feeling of 'shock' in being told that they had PAS. Then participants talked about the difficulty of accepting the diagnosis and emotions associated with it ('You're just so emotionally like, 'Is this really happening?'; and 'I was not in the best mind frame, and was not thinking extremely clearly a lotta the time, just because I was so emotional.')

Several participants related how their shock was compounded by providers' direct and serious style of communication. One participant explained, 'Doctors were kinda blunt'. Participants stated they understood the need for direct communication because of the urgency of the situation, but it was still difficult. For all participants, the diagnosis set off a cascade of events, as this woman explained: '(The doctor said) Okay. We're gonna deliver you in 2 weeks'. 'I'm like, "What?" It happened fast once they finally confirmed it'. Some participants also mentioned that the diagnosis experience was difficult because they received conflicting information about management. Providers often gave unclear or conflicting advice on delivery timing, for example: 'Some doctors saying I could make it 34 weeks, then Dr. (Name) saying 'no way.' It is 32 weeks if you want to live'. Participants also had a difficult time with a lack of certainty about outcomes, as expressed in these quotes:

I think that there's a lot of unknown with this. You might make it to 34 weeks. You might not. You might bleed. You might not. You might have to stay in the hospital the whole time. You might not. There was just so much not definitive answers that I think that's really hard.

Everybody you talked to had a different answer. I will say that's probably the worst part of our experience, and what my husband struggled with them most. Every doctor that would come in every day would have a different answer.

Finally, the lack of alternative treatment options was challenging for participants facing a new diagnosis of PAS and led patients and their partners to feel a sense of medical helplessness. Participants recalled conversations with their providers about treatment options as one-way, with the doctor being highly prescriptive about the course of clinical care. Most participants were told repeatedly that hysterectomy was the only option for treatment. Many noted that this conflicted with information they received from other providers, PAS survivors and information found in researching the topic online. Some participants were not comfortable with this single option for treatment, and others accepted it as necessary to save their lives. For example, one woman said: 'I wasn't comfortable with them taking my uterus and acting like it was an absolute necessity,' and another said: 'I was just 


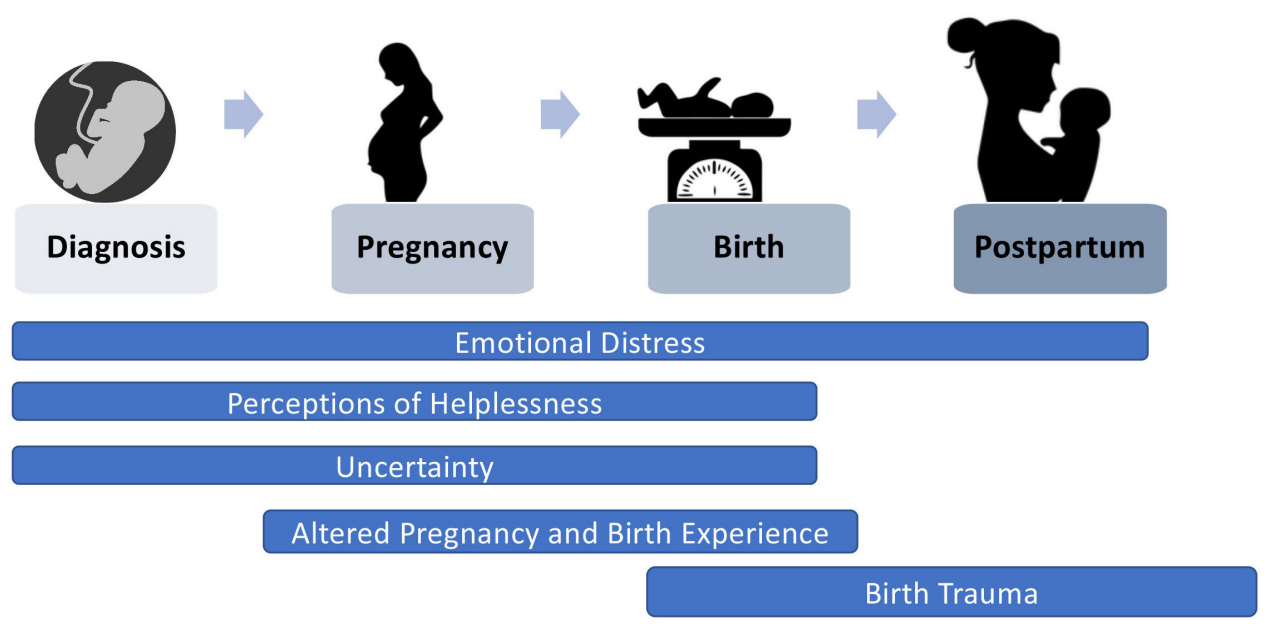

Figure 1 Lived experiences of patients with placenta accreta spectrum across the care continuum.

like-you save me. Do whatever you need to do. I didn't mind that I wasn't in the planning'.

Many participants sought second opinions to explore other treatments or to negotiate aspects of their treatment plan. One participant listed the specific requirements for how she decided where to go for clinical care for PAS 'My list was someone what would try to let me try to get to 36 weeks, someone that would do a horizontal incision. Someone that would let my husband be in the room and let me be awake for the delivery. That was really important to me'. Another participant discussed the lack of options as frustrating, but ultimately accepted treatment with hysterectomy because she saw benefit in it compared with other options: '[I] probably would have still chosen the hysterectomy because we were done having children and the added bonus of no period'.

\section{Pregnancy}

The themes that emerged for lived patient experience in the pregnancy period were similar to the diagnosis stage (emotional distress, medical helplessness), and also included disruptive family changes. During the pregnancy period, emotional distress and medical helplessness mutually reinforced each other. All of the participants discussed their experiences as constantly living in fear; participants often described this as 'survival mode'. The anxiety about possible bleeding and need for frequent monitoring extracted an emotional toll. Many participants stated that it was difficult to process what was happening and that they were just 'surviving' because of this sense of uncertainty and helplessness. One woman described: I lived in fear every day. I feared to walk to the bathroom. I feared to go to the kitchen. I didn't cook. I laid around. Then I was afraid I was gonna get blood clots. Then I was afraid of this. It was just constant fear'. Another woman explained how her life revolved around the danger of her pregnancy:

I was just like a robot. I had a non-stress test and then the next day an ultrasound. Then the next day, another non-stress test and then an ultrasound. I was in the hospital for 2 weeks and then I'm out. I mean, I just lived in it. I just kind of figured that was my new world 'til I got the baby safely out. That was super hard on the family.

Due to the substantial risk of rapid and life-threatening bleeding, all participants had been told by their doctors that they needed to be within 15-30 min of the hospital as the delivery date neared. Ten of the 17 participants relocated from their homes to be closer to the hospital. For many, it was difficult either being away from their family support systems, or taking care of children while taking care of themselves and their pregnancy. The following quotes demonstrate the difficulty of family separation during this time:

That was super hard. I spent a lot of time on Facebook Messenger with them. Sometimes my husband would just put the computer up in the living room, and I would have my computer on at the hospital [hospitalised for monitoring]. I would just be there virtually. They would run up to the computer, and they would talk to me.

I lived with my parents, and I brought my two youngest, who were, I wanna say, four and one at the time, four and one, and then the rest of my children were in school. My husband was back in [city] with my five other children.

Participants discussed how a PAS pregnancy was difficult not just for themselves, but also for their partners, who had to shoulder a larger share of the workload and also worried about the well-being of the pregnant patient and unborn child. Many described the burden on the partner of travelling long distances between home and the hospital, or the taxing effects of prolonged hospitalisation. Some of the participants were in the hospital for a few days and others were admitted for months. Many participants noted that their partner served as a key source of support during the diagnosis and treatment. Participants often expressed that this experience was as 
hard for their partner as it was for them as the pregnant woman. The following quotes capture this sentiment: 'He would come to the hospital, and he was so exhausted. I could just see how tired he was, how worn out he was.'; 'It was still very traumatic for him.'; and 'He was afraid I would die.'

\section{Birth experience}

Participants described birth-related trauma and grief in losing a normal birth experience. Many of the participants discussed a sense of overwhelming fear arising from uncertainty leading up to birth and the trauma of the birth itself. Pregnant patients consistently described their fear of dying during birth and surgery, as described by this participant: 'Mentally, just worrying I was gonna die. Just terrified out of my mind just with all the risks and writing letters to my kids the night before in case I didn't make it'. Participants described their preparation for the birth experience as anticipation of a high-risk surgery and uncertain outcomes. The emphasis on safe surgical care overshadowed or conflicted with any preparation for a joy-filled delivery of their newborn. Many participants mourned the loss of the 'normal birth experience', whereby childbirth would be eagerly anticipated and celebrated. Instead, childbirth was approached with fear and anxiety, as described by these participants:

I had 2 16-gauge IVs, one in each hand. Then I had an artery line put in so they could monitor my heart and everything in every single way they could, monitor my pulse, my pressure, my blood pressure, everything so they could keep an extremely close eye on me where this was a very serious surgery in case there was hemorrhaging or anything.

I knew it was going to be a dangerous surgery going in. Going into my delivery, I was sent to general OR, and put under right away, before they even started the delivery. One of the hardest parts was not knowing, going in, if I was going to make it out alive to even meet my child, or to raise the children that I did have.

The emotional trauma of the birth experience was compounded by uncertainty related to newborn prematurity. Both in the setting of planned and emergent deliveries, participants worried about the outcomes of their newborn premature baby. Participants were struck by the difficulty of not being awake for the birth itself (for some), or only having a few moments to experience birth prior to undergoing general anaesthesia for surgery (for others). After delivery, most participants were ready to go home before their premature newborn, and thus had conflicting feelings about leaving baby in the hospital. Some quotes that capture this experience include: 'It was weird for me to have to leave him in the hospital when I went home.'; and 'Because I had been knocked out,-I saw him for a second I think after they delivered him'.

\section{Postpartum}

Themes that emerged when participants discussed the postpartum period included the often difficult and sometimes prolonged recovery process after leaving the hospital, the lack of knowledge about PAS by general clinical providers after discharge and grief related to loss of fertility. Many of the participants did not anticipate how hard the recovery process would be. This included the physical recovery after a difficult childbirth ('I didn't realize how much that would affect me after going home. Even the first few days in the hospital I felt very weak and lightheaded. That was probably the hardest physically.'), as well as the emotional impact of surviving a lifethreatening pregnancy and childbirth experience ('It's so crazy that I get emotional this far out, a year away.'). Most of the participants were physically exhausted after surgery, which impacted their ability to take care of a newborn. Further, they did not anticipate how difficult it would be to manage complex bladder care, postoperative pain and physical therapy following the caesarean hysterectomy.

Participants noted that they struggled with a lack of knowledge and understanding by postpartum providers who were less familiar with PAS. This began immediately following delivery, as participants described being in the same ward as patients who had undergone 'normal caesareans' and feeling that clinical staff lacked knowledge and understanding about the trauma of their experience. This lack of acknowledgement continued in postpartum care that participants received when they returned home, leading them to feel frustrated and hurt that their birth experience and their postpartum needs were not understood.

...my care was picked up by the urologist here who knew nothing about what I'd been through. Even my [normal] OB doctor who knew what I've been through, it was still different.

In the postpartum period, participants described feelings of grief related to what they had lost in living through a PAS. This grief included the loss of a joyful pregnancy and birth, loss of quality time with their family during the uncertain pregnancy period and loss of their future fertility. For those who experienced a hysterectomy at the time of childbirth, having the option for future pregnancies taken away from them created both sadness and frustration. This participant described how the loss of fertility was one of the hardest aspects of living with PAS:

I think just the whole not being able to decide that it was my last child, was probably the hardest thing. The fact that I didn't get to make that decision on my own, that I had to have the hysterectomy was hard for me.

\section{DISCUSSION}

This study used qualitative methods to identify themes in the lived experiences of patients undergoing diagnosis, 
treatment and recovery from PAS. Themes that were common throughout the care continuum were related to the emotional burden of experiencing PAS, fear and uncertainty related to both maternal and child outcomes and lack of autonomy in regard to medical decisionalmaking. These findings suggest that there is a need for interventions-such as decision tools and education materials-to better prepare and support patients and their families through this process, and to facilitate shared decision-making with clinical providers.

Many of the participants described their experiences with diagnosis and pregnancy as a time of medical helplessness. ${ }^{23}$ Given the urgency and severity of PAS, participants felt that they were at the mercy of the medical establishment, with little personal control or agency over their outcomes. A lack of control over childbirth and a loss of sense of self have been identified as significant contributors to post-traumatic stress disorder following childbirth. ${ }^{24}$ Individuals who experience a traumatic medical event may adapt learnt helplessness strategies as a way to cope, but these strategies may contribute to longterm psychological distress. ${ }^{23}$ Coping-based interventions are needed to support patients with PAS throughout the pregnancy, childbirth and postpartum continuum, in order to protect against emotional distress. Such interventions can help patients and their partners to identify changeable and unchangeable stressors, and apply effective coping behaviours to manage these stressors (eg, appropriate emotion-focused and problem-focused coping strategies).$^{25}$ The results of this study help explain why mental health symptoms appear to be more common in patients diagnosed with PAS compared with the general population of postpartum individuals, ${ }^{10}$ and point to the need to prioritise psychological care for this population.

One of the most prominent themes in our interviews was the life-threatening nature of pregnancy and childbirth for participants. Surviving PAS can be considered a traumatic event, because the experience is marked by the threat of serious injury or death. ${ }^{26}$ Birth trauma is associated with serious postpartum mental health problems such as depression and post-traumatic stress disorder. There are a number of factors that may cause birth trauma, including medical intervention, type of birth experience and perceived loss of control. ${ }^{24}{ }^{27}$ A study by Harris and Ayers found that interpersonal difficulties with care providers, in particular experiencing a lack of support, was associated with birth trauma. ${ }^{28}$ Birth trauma has been defined by the perception of threatened or actual injury or death to the mother or her baby. ${ }^{29}$ Participants in our interviews consistently spoke about their fear of death leading up to labour and delivery. Even if the delivery itself went as planned, sustained fear and anticipation of their life-threatening condition set them up for experiencing debilitating symptoms of post-traumatic stress following childbirth. To reduce birth trauma, patients require improved emotional support from their care providers. ${ }^{30}$ In addition, having greater involvement in the decision-making process may give pregnant patients a greater sense of control over their experience and mitigate development of post-traumatic stress.

Our results expand on similar themes described in another qualitative study with seven patients with PAS from Ireland. ${ }^{12}$ Participants in this study were similarly shocked by the diagnosis of PAS, of which many had never heard before being diagnosed. They, like participants in our study, feared dying during birth and relied heavily on family for support. Participants in this study echoed the themes of birth trauma and ongoing problems after surviving the birth experience, one noting 'it's not all over when you go home'. That there is so much overlap between this study from Ireland and our study from the Intermountain West of the USA suggest that the themes of medical helplessness, uncertainty and birth trauma are likely common among patients diagnosed with PAS.

The loss of fertility is also part of the clinical management of PAS. Participants in this study stated that was one of the difficult experiences with PAS was in having the option for future fertility taken away from them. Some participants discussed how they did not want to accept a hysterectomy as the only option for their care. The lack of involvement in the decision-making process for the management and treatment of PAS and the loss of a future fertility may cause more negative psychological outcomes.

In order to improve emotional outcomes, it is worth exploring the development of tools and interventions to better support patients and clinicians for the management and delivery of PAS. As of now, the primary option for treating PAS is hysterectomy, but uterine-sparing treatments are increasingly used to treat PAS. The decision to pursue either of these options is preference-sensitive, but also depends on the circumstances of the pregnancy and system in which care is received. A PAS decision aid would inform patients of their options, help clarify their values, support their preference construction processes, and enable them to engage more actively in shared decision making with their clinicians. Compared with usual care interventions, decision aids significantly improve knowledge of the options, reduce decisional conflict, and increase the likelihood of shared decision making. ${ }^{31}$ Future research should explore how these types of tools improve patient outcomes.

\section{Implications for practice}

To make an informed decision about these complex treatment options, pregnant patients and partners need to be empowered and engaged in shared decision-making with their provider. Shared decision-making is particularly useful when there are no clear 'best' options (ie, when there is 'clinical equipoise'), and where decisions are value-laden and complex. ${ }^{32} 33$ The results of this study suggest that there are opportunities for shared decisionmaking even when pursuing a hysterectomy, such as type of skin incision, type of anaesthesia and other delivery preferences that may be informed with a decision aid. 


\section{Limitations}

There are limitations to this research. It is possible our sample of participants do not represent the general population of patients with PAS. Our study did not include patients who had previable or extremely preterm $(<28$ weeks gestation) deliveries, and none of the participants had unexpected PAS that was diagnosed at delivery. Understanding the lived experiences of these patients is an important knowledge gap we did not address. Most of the individuals who agreed to be interviewed were nearing completion of their intended family size before being diagnosed with PAS. Those who are earlier in their reproductive lives may have responded differently. The sample lacks racial and ethnic diversity and is limited geographically to the Intermountain Region of the USA. It is, however, the largest study of structured interviews in patients with PAS. Also, those who agreed to be interviewed may not represent all patients with PAS. However, the pervasive themes in this study, and consistency with existing literature, suggest that these experiences may not be unique. Future research should examine the experiences of patients with PAS with a broader and more diverse population.

\section{Conclusion}

Patients with PAS experienced care that conflicted with their goals for pregnancy and birth. Many participants stated how grateful they were for lifesaving treatment, but still struggled with their experience of navigating diagnosis, management, birth and postpartum recovery with PAS. In each of these domains, patient's needs were not completely met. Because of the serious nature of a PAS diagnosis and the radical nature of treatment, patients experienced uncertainty and medical helplessness. This lost autonomy and lack of involvement in decisionmaking is likely associated with dissatisfaction and distress. Finally, patients experienced the alteration of the birth experience and birth-related trauma that lasted long after delivery. These lived experiences suggest that there is a critical unmet need to understand and improve the management and care of patients with PAS, focused on patient experience. We believe that work to develop a decision aid that engages patients in shared decisionmaking is the next best step. Further, health systems specialising in PAS care should build systems and pathways that optimally support the social, psychological and emotional needs of these patients and their families from diagnosis through full recovery.

Contributors All authors meet all four ICMJE criteria for authorship. BDE, ER and RS conceived of the study idea. ER performed semi-structured interviews. BS coded interview transcripts. BS and ER independently reviewed and audited codes, groupings and themes for accuracy and rigour. BS, MHW, ER and BDE queried the codes and reviewed the thematic results. BDE and ER drafted the manuscript. All authors critically revised the manuscript drafts and approve of the final manuscript. All authors agree to be accountable for the accuracy and integrity of the work. BDE is the guarantor for this manuscript and accepts full responsibility for the work and conduct of this study, had access to the data, and controlled the decision to publish.
Funding Research reported in this publication was supported by Eunice Kennedy Shriver National Institute of Child Health and Human Development under award number K23HD106009.

Disclaimer The content is solely the responsibility of the authors and does not necessarily represent the official views of the National Institutes of Health.

Competing interests None declared.

Patient and public involvement Patients and/or the public were involved in the design, or conduct, or reporting, or dissemination plans of this research. Refer to the Methods section for further details.

Patient consent for publication Not applicable.

Ethics approval Ethical approval for the study was obtained from the University of Utah Institutional Review Board (IRB 00135884).

Provenance and peer review Not commissioned; externally peer reviewed.

Data availability statement Data are available upon reasonable request. Deidentified data are available upon reasonable request.

Open access This is an open access article distributed in accordance with the Creative Commons Attribution Non Commercial (CC BY-NC 4.0) license, which permits others to distribute, remix, adapt, build upon this work non-commercially, and license their derivative works on different terms, provided the original work is properly cited, appropriate credit is given, any changes made indicated, and the use is non-commercial. See: http://creativecommons.org/licenses/by-nc/4.0/.

ORCID iD

Brett D Einerson http://orcid.org/0000-0003-1928-4333

\section{REFERENCES}

1 Jauniaux E, Bunce C, Grønbeck L, et al. Prevalence and main outcomes of placenta accreta spectrum: a systematic review and meta-analysis. Am J Obstet Gynecol 2019;221:208-18.

2 Carusi DA. The placenta accreta spectrum: epidemiology and risk factors. Clin Obstet Gynecol 2018;61:733-42.

3 Silver RM, Branch DW. Placenta accreta spectrum. N Engl J Med 2018;378:1529-36.

4 Silver RM, Landon MB, Rouse DJ, et al. Maternal morbidity associated with multiple repeat cesarean deliveries. Obstet Gynecol 2006;107:1226-32.

5 O'Brien JM, Barton JR, Donaldson ES. The management of placenta percreta: conservative and operative strategies. Am J Obstet Gynecol 1996;175:1632-8.

6 Eller AG, Porter TF, Soisson P, et al. Optimal management strategies for placenta accreta. BJOG 2009;116:648-54.

7 Bailit JL, Grobman WA, Rice MM, et al. Morbidly adherent placenta treatments and outcomes. Obstet Gynecol 2015;125:683-9.

8 Zuckerwise LC, Craig AM, Newton JM, et al. Outcomes following a clinical algorithm allowing for delayed hysterectomy in the management of severe placenta accreta spectrum. Am J Obstet Gynecol 2020;222:179.e1-179.e9.

9 Tol ID, Yousif M, Collins SL. Post traumatic stress disorder (PTSD): the psychological sequelae of abnormally invasive placenta (AIP). Placenta 2019;81:42-5.

10 Grover B, Einerson BD, Keenan KD, et al. Patient-Reported health outcomes and quality of life after peripartum hysterectomy for placenta accreta spectrum. Am J Perinatol 2020 doi:10.1055/s-0040-1715465

11 Terlizzi K. The million dollar cesarean. Narrat Inq Bioeth 2017;7:211-3.

12 Bartels HC, Mulligan KM, Lalor JG, et al. A life changing experience: an interpretative phenomenological analysis of women's experiences of placenta accreta spectrum. Eur J Obstet Gynecol Reprod Biol 2020;254:102-8.

13 O'Brien BC, Harris IB, Beckman TJ, et al. Standards for reporting qualitative research: a synthesis of recommendations. Acad Med 2014;89:1245-51.

14 Frazier LM, Miller VA, Horbelt DV, et al. Comparison of focus groups on cancer and employment conducted face to face or by telephone. Qual Health Res 2010;20:617-27.

15 7.0.23 DV. Web application for managing, analyzing, and presenting qualitative and mixed method research data Los Angeles, CA: SocioCultural Research Consultants 2021.

16 Elo S, Kyngäs $\mathrm{H}$. The qualitative content analysis process. J Adv Nurs 2008;62:107-15. 
17 Rothwell E, Lamb B, Johnson E, et al. Patient perspectives and experiences with in vitro fertilization and genetic testing options. Ther Adv Reprod Health 2020;14:263349411989994.

18 Hennink MM, Kaiser BN, Marconi VC. Code saturation versus meaning saturation: how many interviews are enough? Qual Health Res 2017;27:591-608.

19 Miles MB, Huberman AM, Saldana J. Qualitative data analysis: a methods sourcebook. Thousand Oaks: Sage, 2014.

20 Elo S, Kyngäs H. The qualitative content analysis process. J Adv Nurs 2008;62:107-15.

21 Mason J. Qualitative researching. 2nd edn. London: Sage Publications, 2002.

22 Miles M, Huberman A, Saldana J. Qualitative data analysis. 4th edn. London: Sage Publicaitons, 2019.

23 Sullivan DR, Liu X, Corwin DS, et al. Learned helplessness among families and surrogate decision-makers of patients admitted to medical, surgical, and trauma ICUs. Chest 2012;142:1440-6.

24 Canfield D, Silver RM. Detection and prevention of postpartum posttraumatic stress disorder: a call to action. Obstet Gynecol 2020;136:1030-5.

25 Fontein-Kuipers Y, van Limbeek E, Ausems M, et al. Responding to maternal distress: from needs assessment to effective intervention. Int J Public Health 2017;62:441-52.
26 Pai A, Suris AM, North CS. Posttraumatic stress disorder in the DSM-5: controversy, change, and conceptual considerations. Behav Sci 2017;7:7.

27 Moyzakitis W. Exploring women's descriptions of distress and/or trauma in childbirth from a feminist perspective. Evidence-Based Midwifery 2004;2.

28 Harris R, Ayers S. What makes labour and birth traumatic? A survey of intrapartum 'hotspots'. Psychol Health 2012;27:1166-77.

29 Beck CT, Watson S. Subsequent childbirth after a previous traumatic birth. Nurs Res 2010;59:241-9.

30 Bastos MH, Furuta M, Small R. Debriefing interventions for the prevention of psychological trauma in women following childbirth. Cochrane Database Syst Rev 2015;4:CD007194.

31 Stacey D, Légaré F, Lewis K, et al. Decision AIDS for people facing health treatment or screening decisions. Cochrane Database Syst Rev 2017;2017.

32 Kon AA, Ackerson L, Lo B. How pediatricians counsel parents when no "best-choice" management exists: lessons to be learned from hypoplastic left heart syndrome. Arch Pediatr Adolesc Med 2004;158:436-41.

33 Byrne PJ, Murphy A. Informed consent and hypoplastic left heart syndrome. Acta Paediatr 2005;94:1171-5. 